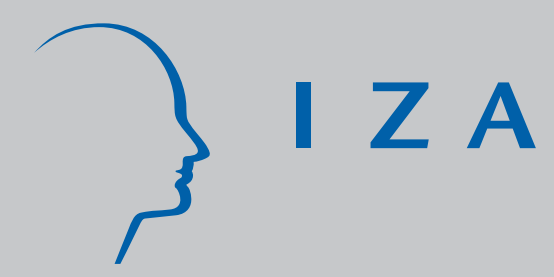

IZA DP No. 2107

Empirical Estimation Results of a

Collective Household Time Allocation Model

Chris van Klaveren

Bernard van Praag

Henriette Maassen van den Brink

April 2006 


\title{
Empirical Estimation Results \\ of a Collective Household Time Allocation Model
}

\author{
Chris van Klaveren \\ SCHOLAR, University of Amsterdam \\ Bernard van Praag \\ SCHOLAR, University of Amsterdam \\ and IZA Bonn \\ Henriette Maassen van den Brink \\ SCHOLAR, University of Amsterdam
}

Discussion Paper No. 2107

April 2006

IZA

P.O. Box 7240

53072 Bonn

Germany

Phone: +49-228-3894-0

Fax: +49-228-3894-180

Email: iza@iza.org

\begin{abstract}
Any opinions expressed here are those of the author(s) and not those of the institute. Research disseminated by IZA may include views on policy, but the institute itself takes no institutional policy positions.

The Institute for the Study of Labor (IZA) in Bonn is a local and virtual international research center and a place of communication between science, politics and business. IZA is an independent nonprofit company supported by Deutsche Post World Net. The center is associated with the University of Bonn and offers a stimulating research environment through its research networks, research support, and visitors and doctoral programs. IZA engages in (i) original and internationally competitive research in all fields of labor economics, (ii) development of policy concepts, and (iii) dissemination of research results and concepts to the interested public.
\end{abstract}

IZA Discussion Papers often represent preliminary work and are circulated to encourage discussion. Citation of such a paper should account for its provisional character. A revised version may be available directly from the author. 


\section{ABSTRACT \\ Empirical Estimation Results of a Collective Household Time Allocation Model ${ }^{\star}$}

In this paper an empirical model is developed where the collective household model is used as a basic framework to describe the time allocation problem. The collective model views household behavior as the outcome of maximizing a household utility function which is a weighted sum of the utility functions of the male and the female. The empirical research that has been done is mainly focused on testing and refuting the unitary model. Moreover, in the bulk of time allocation literature the main accent still lies on the development of theory. The novelty of this paper is that we empirically estimate the two individual utility functions and the household power weight distribution, which is parameterized per household. The model is estimated on a sub-sample of the British Household Panel Survey, consisting of two-earner households. The empirical results suggest that: (1) Given that the weight distribution is wage dependent, preferences of males and females differ, which rejects the unitary model; (2) The power differences are mainly explained by differences in the ratio of the partners' hourly wages; (3) Although there are significant individual variations on average the power distribution in two-earner families is about even; (4) The male tends to be marginally more productive in performing household tasks than the female (5) The preference for total household production is influenced by family size for the female but not for the male (6) Both males and females have a backward bending labor supply curve.

JEL Classification: D12, D13, J22

Keywords: collective household models, labor supply, intra-household, time allocation

Corresponding author:

Chris van Klaveren

SCHOLAR

Department of Economics and Econometrics

University of Amsterdam

Roetersstraat 11

Room 11.09, Building E

1018 WB Amsterdam

The Netherlands

Email: c.p.b.j.vanklaveren@uva.nl

\footnotetext{
${ }^{*}$ We are grateful to Frederic Vermeulen for his constructive remarks.
} 


\section{Introduction}

In recent years there has been a renewed interest for the problem what is going on within the household regarding the decision process on time allocation. How can the decision process be accurately described when we observe only the outcomes in terms of labor and household work supplied by the spouses? Within the household some group decision process is working and the results are important for society as a whole. It translates into the labor supply of males and females, fertility, and the demand for child care.

In fact households face two interconnected decision problems. The first problem is how to divide the hours of male and female over the different time spending categories. The second problem is how to divide the income earned among various consumption spending categories. In this paper we explain the 'time spending' problem, while we leave the consumer spending problem aside, partly because we miss the relevant information in our data set (see Browning \& Gørtz (2005) where time and money spending is studied simultaneously).

At the moment there are three dominant approaches regarding household behavior (see Vermeulen (2002) for a thorough survey). The first and oldest is the unitary approach, where the household is considered as a unit with its own utility function. Unitary models are criticized because it is implicitly assumes that all household members in a multi-person household have identical preferences or that there is one decision maker. The optimal time allocation scheme of individuals depends solely on comparative advantages and not on who generates income or who benefits from a change in time spending. Many empirical 
papers provide evidence that households cannot be seen as single units (See for example Browning, Bourguignon, Chiappori \& Lechene (1994), Lundberg, Pollak \& Wales (1997), Ward-Batts (2002), Thomas (1990), Browning \& Chiappori (1998) and others).

The second approach is the other extreme, where household partners do not cooperate at all (Leuthold (1968), Ashworth \& Ulph (1981), Browning (2000), Chen \& Woolley (2001)) and Kooreman \& Kapteyn (1990). That is, each partner optimizes his or her own utility and takes the behavior of the other as given. This context will yield a non-cooperative Nash equilibrium.

The third approach is the collective approach. In this approach male and female have their own utility function and the household equilibrium is Paretoefficient. This research line has been initiated by Chiappori (1988). It can be shown that the partners behave as if the household $n$ optimizes a collective utility function $U_{h, n}=\pi_{n} \cdot U_{m, n}+\left(1-\pi_{n}\right) \cdot U_{f, n}$, where $\pi_{n}$ may be interpreted as the power of the male and consequently $\left(1-\pi_{n}\right)$ as the power of the female in the household $n$ (see Chiappori $(1988,1997)$, Apps \& Rees (1997) and Browning and Chiappori (1998)). Notice that this collective utility function has the individual utilities of the partners as arguments.

The empirical research that has been done is mainly focused on testing and refuting the assumptions of the unitary model. In the bulk of time allocation literature the main accent still lies on the development of theory, while relatively few authors attempt an empirical approach as well. A few exceptions are McElroy (1990), Carlin (1990), Beblo (1999), Blundell, Chiappori, Magnac 
\& Meghir (2001), Hallberg \& Klevmarken (2003), Browning \& Gørtz(2005). Empirical papers that focus on the timing of certain activities are, Hamermesh (1996, 2000, 2002), Jenkins \& Osberg (2005), Hallberg (2003) and Van Klaveren \& Maassen van den Brink (2005).

In the present paper we estimate a collective household model of time allocation using the British Household Panel Survey (BHPS). Specifying the individual utility functions as additive log-functions, we estimate the male's and the female's utility function, where we assume that individual utilities depend on time spent on household work, on leisure and on the job. In addition we add for both individuals as utility determinants the household income and the 'household care level', which we operationalize as the sum of the hours worked by male and female in the household .

Moreover, we estimate which determinants explain the power distribution between male and female. As a result we assess the wage, child and non-labor household income effects on the time spending behavior of both partners.

In view of the problems involved we restrict ourselves to a subsample of households where both partners have a paid job. This is clearly a restriction, since we exclude those households where only one or no partner is at work and where we would find corner solutions.

In section 2 we develop the collective model we are planning to estimate. In section 3 the estimation method is described. A SUR-application is sufficient to estimate this non-linear model. In section 4 the estimation results are presented and finally, in section 5 the results are evaluated and discussed. 


\section{The Model}

We assume that both partners have a log-additive utility function in time spendings, household income $(Y)$, and the joint household care level $(H)$. The male's utility function is

$$
\begin{aligned}
U_{m} & =\alpha_{m, 1} \ln \left(l e_{m}\right)+\alpha_{m, 2} \ln \left(w h_{m}\right)+\alpha_{m, 3} \ln (H) \\
& +\alpha_{m, 3 I} \ln (f s+1) \cdot \ln (H)+\alpha_{m, 4} \ln (Y)+\alpha_{m, 5} \ln \left(T-l e_{m}-w h_{m}\right)
\end{aligned}
$$

where household income $Y$ equals

$Y=w_{m}\left(T-l e_{m}-w h_{m}\right)+w_{f}\left(T-l e_{f}-w h_{f}\right)+y_{u}$

and household care level $H$ is defined as

$H=w h_{m}+\gamma \cdot w h_{f}$

The total weekly time endowment of 168 hours is denoted as $T$. The net wage rates of male and female are denoted by $w_{m}$ and $w_{f}$, respectively. The $y_{u}$-term stands for the net weekly non-labor household income. The $f s$-term, referred to as family size, stands for the number of children that are present in the household. The first term $l e_{m}$ refers to the male's weekly leisure hours, the second term $w h_{m}$ to weekly hours spent on household work, the third term refers to the level of total household production $H$, defined as the total number of weekly household hours supplied by both partners given the ratio of productivity in the household of male and female.We notice that this linear specification is an approximation of a non-linear concept, as the substitution 
ratio between males and females is probably variable over the whole range. The fourth term is the interaction of joint household production with family size. The second and third/fourth term make it possible to distinguish between the effort of individual household chores and the joint effect of a smoothly managed household as a product of both partners' household efforts. The fifth term refers to the household's monetary income and the sixth term refers to the utility (or disutility) for the individual derived from working in a paid job.

We will distinguish four different alternatives:

- Alternative 1: $\gamma=1$ and $\alpha_{m, 3 I}=0$.

- Alternative 2: $\gamma=1$ and $\alpha_{m, 3 I}$ to be estimated

- Alternative 3: $\gamma$ to be estimated and $\alpha_{m, 3 I}=0$

- Alternative 4: $\gamma$ to be estimated and $\alpha_{m, 3 I}$ to be estimated.

While we assume for the first and second alternative that the number of household hours of male and female are perfect substitutes, this assumption is relaxed in the third and fourth alternative. For the second and fourth alternative an interaction term is included, where the effect of joint household production depends on family size. For simplicity, we will discuss the first alternative in the section where we explain the model and the estimation method. Hence, the $\gamma$-parameter is set equal to one and $\alpha_{m, 3 I}$ is set equal to zero. Alternatives one up to three are nested in the model according to alternative four.

For identification purposes we assume that the utility function is linearly homogeneous, i.e. $\sum_{1}^{5} \alpha_{m, i}=1$. 
A similar utility function $U_{f}$ is assumed for the female. Notice that the income budget constraint and the time constraints are incorporated in the utility function itself.

According to the collective approach we may view household $n$ 's behavior as the outcome of maximizing a household utility function of the following type:

$$
U_{n, h}=\pi_{n} U_{n, m}+\left(1-\pi_{n}\right) U_{n, f}
$$

where the power coefficient $\pi$ varies over households.

When the optimization problem is described in the Lagrangian form it follows that the household utility function is concave given explicit linear constraints. Hence, there exists one unique optimum.

Let us assume that the male is setting his leisure time at $l e_{m}$ and his household production hours at $w h_{m}$ and as a consequence his job hours at $j h_{m}=\left(T-l e_{m}-w h_{m}\right)$ such that the collective utility function is maximized. The corresponding first-order-conditions (FOC) for the male's leisure time and hours of household work are then after re-ordering

$$
\begin{gathered}
\frac{\partial U_{h}}{\partial l_{m}}=\frac{\partial U_{f}}{\partial l e_{m}}+\pi\left(\frac{\partial U_{m}}{\partial l e_{m}}-\frac{\partial U_{f}}{\partial l e_{m}}\right)=0 \\
\frac{\partial U_{h}}{\partial w h_{m}}=\frac{\partial U_{f}}{\partial w h_{m}}+\pi\left(\frac{\partial U_{m}}{\partial w h_{m}}-\frac{\partial U_{f}}{\partial w h_{m}}\right)=0
\end{gathered}
$$


For the female we find two similar equations. We notice that each of the FOC's in (3) and (4) consists of three terms. The first and the third term refer to the 'female' part of the collective utility function. This is due to the fact that household income and the total household production figure in the utility functions of both partners. The hours $w h_{f}$ that the female works in the household affects the level of well-being of the male. The same holds for the job working hours $j h_{m}$ of the female, because the net wage of the female is part of the household income.

There is no need to spell out all the FOC's in detail. Let us consider the first FOC in more detail. Obtaining the derivative $\frac{\partial U_{m}}{\partial l_{m}}$ gives:

$$
\frac{\partial U_{m}}{\partial l e_{m}}=\frac{\alpha_{m, 1}}{l e_{m}}-\frac{\alpha_{m, 4} \cdot w_{m}}{w_{m}\left(T-l e_{m}-w h_{m}\right)+w_{f}\left(T-l e_{f}-w h_{f}\right)+y_{u}}-\frac{\alpha_{m, 5}}{T-l e_{m}-w h_{m}}
$$

The other derivative in (3) yields a similar expression. Hence (3) may be interpreted as a linear expression in the utility parameters $\left(\alpha_{m}, \alpha_{f}\right)=$ $\alpha$ of the male and female and coefficients that are non-linear expressions in $l e_{m}, l e_{f}, w h_{m}, w h_{f}, w_{m}, w_{f}$. For instance, the first coefficient may be denoted as $x_{1, m, 1}=\frac{1}{l e_{m}}$. As $\alpha_{m, 2}$ does not appear in the first FOC we have $x_{1, m, 2}=0$. We shortly denote the coefficient vector of the first FOC, referring to the male's utility function, by a vector function $x_{1, m}\left(l e_{m}, l e_{f}, w h_{m}, w h_{f}, w_{m}, w_{f}\right)$. More concisely, we may write the first FOC as

$$
x_{1 f}^{\prime} \alpha_{f}+\pi\left(x_{1 m}^{\prime} \alpha_{m}-x_{1 f}^{\prime} \alpha_{f}\right)=0
$$


where $\alpha$ stands for a 10 -vector of utility parameters and $x_{1}^{\prime}=\left(x_{1 m}^{\prime}, x_{1 f}^{\prime}\right)$ for a ten- dimensional vector function of $l e_{m}, l e_{f}, w h_{m}, w h_{f}, w_{m}, w_{f}$. The index 1 refers to the $x$ - vector in the first FOC. In a similar way the other FOC's with respect to $w h_{m}, l e_{f}$ and $w h_{f}$ can be determined. Hence, this yields a system of four equations

$$
\left[\begin{array}{c}
\pi x_{1 m}^{\prime}+(1-\pi)\left(x_{1 f}^{\prime}\right) \\
\pi x_{2 m}^{\prime}+(1-\pi)\left(x_{2 f}^{\prime}\right) \\
\pi x_{3 m}^{\prime}+(1-\pi)\left(x_{3 f}^{\prime}\right) \\
\pi x_{4 m}^{\prime}+(1-\pi)\left(x_{4 f}^{\prime}\right)
\end{array}\right] \alpha=\left[\pi X_{m}^{\prime}+(1-\pi) X_{f}^{\prime}\right] \alpha=0
$$

where $X_{m}^{\prime}$ and $X_{f}^{\prime}$ are $(4 \times 10)$-matrices. For household $n$ we define the matrix $X_{n, h}^{\prime}$ by

$$
\left[\pi_{n} X_{n, m}^{\prime}+\left(1-\pi_{n}\right) X_{n, f}^{\prime}\right]=X_{n, h}^{\prime}
$$

For convenience, we introduce the short-hand notation $z=\left(l e_{m}, w h_{m}, l e_{f}, w h_{f}\right)$ for the solution vector. The left-hand-side of system (6) is the gradient of the household utility function $U_{h}(z)$. We shall write it sometimes as the 4vector $U_{h}^{\prime}(z)$ or alternatively as $U_{z}$. The above system describes the equilibrium where the gradient vector equals the zero vector. Similarly we will denote the $(4 \times 4)$-matrix of second-order derivatives of $U_{h}(z)$ by $U_{h}^{\prime \prime}$ or $U_{z z}$.

The weight distribution between male and female, described by the power coefficient $\pi$, is assumed to depend on their personal characteristics, in short a 
vector $\left(v_{m}, v_{f}\right)$ of power characteristics.

In this paper we restrict ourselves to the following power characteristics: the hourly wages of the two partners, the number of children and the ages of the two partners. Furthermore, we consider the weekly non-labor income. Considering for the moment only the hourly wages of the two partners we specify

$$
\pi_{n}(v)=N\left(\beta_{m} \ln \left(w_{n, m}\right)+\beta_{f} \ln \left(w_{n, f}\right)\right)
$$

where $N($.$) stands for the standard normal distribution function. The advan-$ tage of this specification is that there always holds $\pi(v) \in[0,1]$. If $\beta_{m}=-\beta_{f}$, and $w_{m}=w_{f}$, we find $\pi(v)=\frac{1}{2}$. An increase of $\pi$ implies that the utility function of the male is weighted more heavily in the collective utility function at the expense of the utility of the female. The weight $\pi(v)$ is expected to be increasing in the male's wage and is expected to be decreasing in the female's wage. If $\beta_{m} \neq \beta_{f}$, the weight is asymmetric, that is, even if $w_{m}=w_{f}$, we may have $\pi(v) \neq \frac{1}{2}$. When we would add a constant $\beta_{0}$, one of the partners utility function is structurally overweighed. For example, if $\beta_{0}>0$, this means that the utility function of the male is structurally overweighed. However, as we find in our empirical estimates a statistically insignificant value for $\beta_{0}$, we drop it from our model.

As is mentioned by Browning, Chiappori \& Lechene (2004), a model that is making use of a power function is usually referred to as a collective model. They conclude that when the power function is not assumed to depend on prices (or in our model wages) then the model is equivalent to the standard unitary 
model. The dependency of the power function on wage rates is therefore a crucial element in our model.

\section{The Estimation Method.}

Let us assume we have a data set $\left\{l e_{m, n}, l e_{f, n}, w h_{m, n}, w h_{f, n}, w_{m, n}, w_{f, n}\right\}_{n=1}^{N}=$ $\left\{z_{n}, w_{n}\right\}_{n=1}^{N}$ of $N$ observations of households $n$. Clearly, as econometricians are used to do, we can try to solve the system of FOC's for each $n$ yielding predicted values $\widehat{l e}_{m, n}, \widehat{l e}_{f, n}, \widehat{w h}_{m, n}, \widehat{w h}_{f, n}$ as a function of the individual wages $w_{m, n}, w_{f, n}$ and the unknown parameter vector $(\alpha, \beta)$. However, those functions would be highly non-linear in $\alpha$ and $\beta$ and consequently it would be difficult to estimate the unknown parameters. We propose a more convenient indirect estimation method, similar to the Wald-test criterion, in order to estimate the unknown parameter vector $(\alpha, \beta)$.

Consider the system

$$
\left[\pi_{n} X_{n, m}^{\prime}+\left(1-\pi_{n}\right) X_{n, f}^{\prime}\right]\left[\begin{array}{c}
\alpha_{m} \\
\alpha_{f}
\end{array}\right]=0 \quad \forall n
$$

where we assume for a start that the $\pi_{n}$ are known. Obviously the matrix equality will not hold exactly; so we assume that

$$
X_{n}^{\prime} \alpha=\varepsilon_{n}
$$

where we introduce the error vector $\varepsilon \sim N\left(0, \Sigma_{\varepsilon}\right)$ and we assume that the 
behavior of distinct households is not correlated, that is, $E\left(\varepsilon_{n}, \varepsilon_{n^{\prime}}\right)=0$ if $n \neq n^{\prime}$. The $(4 \times 4)$-error-covariance-matrix $\Sigma_{\varepsilon}$ may be non-diagonal.

The obvious way to estimate this system is to minimize the sum of squared residuals $\sum_{1}^{N} \varepsilon_{n}^{\prime} \Sigma_{\varepsilon}^{-1} \varepsilon_{n}=\sum_{1}^{N} \alpha^{\prime} X_{n} \Sigma_{\varepsilon}^{-1} X_{n}^{\prime} \alpha$ with respect to $\alpha$. We exclude the 'trivial' solution $\alpha=0$ by adding the two identifying conditions $\sum \alpha_{m}=1$ and $\sum \alpha_{f}=1$. Note that, if $\pi_{n}$ would be the same for each household $n$, there is a problem in separately identifying the parameters $\alpha_{m, 3}$ and $\alpha_{f, 3}$ as the same variable $\left(w h_{m}+w h_{f}\right)$ appears in the utility function of both partners. We would only be able to identify their sum $\left(\alpha_{m, 3}+\alpha_{f, 3}\right)$. However, since $\pi_{n}$ is household specific, identification is feasible. The same holds for $\alpha_{m, 4}$ and $\alpha_{f, 4}$.

The estimation problem is solved by iteration. We start by assuming $\beta_{m}=$ $\beta_{f}=1$, yielding first-round power coefficients $\pi_{n}^{(1)}$. Notice that these coefficients are not constant, as households differ with respect to wages $w_{m}$ and $w_{f}$. Then we estimate the $\alpha^{\prime} s$, given $\pi_{n}^{(1)}$.

Consider the system of four equations

$$
y_{n}=X_{n}^{\prime} \alpha+\varepsilon_{n}
$$

where we introduce the nuisance vector $y_{n}$. The system can be estimated by the method of Seemingly Unrelated Least Squares (SUR). If we set $y_{n}=0$ for all $n$, estimation of this system under the constraints $\sum \alpha=1$ is equivalent to minimizing $\sum_{1}^{N} \alpha^{\prime} X_{n} \Sigma_{\varepsilon}^{-1} X_{n}^{\prime} \alpha$ with respect to $\alpha$ under the constraints.

The estimation of the collective model is somewhat more complex as we have to estimate the parameters $\beta_{m}, \beta_{f}$ as well, which requires a non-linear 
estimation method. On the basis of the first-round estimate $\alpha^{(1)}$, we estimate $\beta_{m}^{(1)}, \beta_{f}^{(1)}$. Using these estimated $\beta$-values we then obtain $\pi^{(2)}$. With $\pi^{(2)}$ we estimate $\alpha^{(2)}$ and we continue this iterative process until convergence is reached.

The asymptotic covariance matrix $\Sigma_{\alpha, \beta}$ of the parameter estimates $(\widehat{\alpha}, \widehat{\beta})$ is derived in the usual way.

For alternatives 2 up to 4 it holds that we can estimate $\gamma, \alpha_{m, 3 I}$ and $\alpha_{f, 3 I}$ using the method described above. Notice that, when we include an interaction effect, $\alpha_{m, 3 I}$ and $\alpha_{f, 3 I}$ are considered in the appropriate parameter restriction such that the sum of all preference parameters is equal to 1 for male and female.

\section{Data and Estimation Results.}

We use the 2001-wave $(J)$ of the British Household Panel Survey $(B H P S)$, where we consider a subset of 1497 two-earner households. These households were interviewed between September 2000 and September 2001. The BHPS began in 1991 and is household based, where each adult member of the household is interviewed each year. The main objective of the BHPS is to give insight in the social and economic changes at the individual and household level in the UK.

The information that is used for this study has been derived from questions on how individuals of two-earner households allocate their time. From the proposed empirical model it follows that we are interested in the number of hours that individuals spend on leisure, household tasks and on their jobs. 
Table 1 shows the summary statistics on the weekly hours spent on these different activities by males and females. Furthermore, Table 1 shows the net hourly wage rates of males and females.

\section{-Insert Table 1 about here-}

Not surprisingly, the descriptive statistics indicate that males spend more time on paid labor than females, while the opposite is true for the time spent on household activities. The hourly wage rate is higher for males than for females.

Given the observed quantities of time that are allocated to certain activities and assuming that individuals maximize their utility following the collective model we can estimate the preference parameters $\left(\alpha_{m}, \alpha_{f}\right)$ for the four different alternatives. Table 2 presents these parameter estimates for $\left(\alpha_{m}, \alpha_{f}\right)$.

\section{-Insert Table 2 about here-}

While in the first and second alternative it is assumed that household hours of male and female are perfect substitutes $(\gamma=1)$ this is not assumed in the third and fourth alternative. In order to asses $\gamma$ we let $\gamma$ vary with a gridwidth of 0.025 . For each alternative where $\gamma$ varies, we chose that value of $\gamma$ that gave the highest log-likelihood of the linear parameters. The differences in log-likelihood between the four different alternatives are non-significant.

The $\gamma$-parameters are 0.85 and 0.925 for respectively the third and fourth alternative. This result suggests that the male is slightly more productive than the female. This might be explained due to the fact that females spend on average 
more time on household tasks and the fact that we use a linear approximation of $H$.

When concentrating on the preference parameters we notice that the interaction parameter drops out of the model for alternative one and three and hence there are no estimation results for the interaction of family size with the total household production. We see that all parameter values are significant with exception of the interaction effect of total household production with family size for the male in alternative two and four.

The estimation results appear to be robust for the different alternatives. The main variables in the utility function for the four different alternatives appear to be leisure and household income, for both male and female. The preference for total household production is influenced by family size for the female, while this is not the case for the male.

A Wald-test is be performed to see if the preference parameters of male and female are equal. The test results are printed in Table 3:

\section{-Insert Table 3 about here-}

An $x$ indicates that the parameters are significantly different from one another, while a 0 indicates that the parameters are not significantly different from one another. The test on equality reveals that the coefficients for males and females are in general significantly different. The exceptions are the preference parameter for household work in alternative one and the preference parameter for joint household production in alternative two and four. Furthermore, since the power function is price (wage) dependent, the household utility function is 
not similar to the unitary utility function (see Browning, Chiappori \& Lechene (2004)). Hence, the empirical results suggest that the unitary household model, which is embedded as a special case in the collective model, has to be rejected.

In order to get some more insight in the estimates of Table 2 we can derive the exchange rate between leisure hours and job hours for male and female. Since the coefficients between the four different alternatives are quite similar we will only derive the exchange rate between leisure hours and job hours for the first alternative. The exchange rates for the other alternatives are approximately equal. The exchange rate between leisure hours and job hours for the male is given by

$$
\frac{\partial U_{m}}{\partial l e_{m}} \cdot \Delta l e_{m}+\frac{\partial U_{m}}{\partial j h_{m}} \cdot \Delta j h_{m}=0
$$

From (12) we can derive

$$
\alpha_{m, 1} \cdot\left(1 / l e_{m}\right) \cdot \Delta l e_{m}+\alpha_{m, 4} \cdot\left(1 / y_{h}\right) \cdot w_{m} \cdot \Delta j h_{m}+\alpha_{m, 5} \cdot\left(1 / j h_{m}\right) \cdot \Delta j h_{m}=0
$$

From Table 1 we can obtain the average net hourly wage of the male $(7.947$ pound) and the average net household income per week $(£ 349+£ 209=£ 558)$. From Table 2 we obtain the estimates of the preference parameters and we find

$$
0.755 \cdot \frac{1}{119} \cdot \Delta l e_{m}+0.261 \cdot \frac{7.947}{349+209} \cdot \Delta j h_{m}-0.033 \cdot \frac{1}{44} \cdot \Delta j h_{m}=0
$$


Then we get

$$
0.006 \cdot \Delta l e_{m}+(0.004-0.001) \Delta j h_{m}=0
$$

It follows that the shadow price of one leisure hour is worth about $\frac{1}{2}$ job hour and accordingly its money value would be about $\frac{1}{2}$ of the males hourly wage. Doing the same for females, we find that the shadow price of one hour of female leisure is worth about $\frac{1}{7}$ job hour and its money value $\frac{1}{7}$ of the female's hourly wage.

In Table 4 we present the parameters of the power function for the four different alternatives. We see that the hourly wage rates are most important. The weight of the male's wage is about equal to that of the female, while the sign of the female coefficient is negative as we expected. The female gets additional power if there are children in the first alternative, where children below 5 get more weight compared to children of 5 years and older, while the effect of children above 11 years is non-significant. This child effect is not found for the other alternatives.

The non-labor household income is marginally significant for the first alternative and non-significant in all other alternatives.

The average power coefficient $\left(\bar{\pi}_{n}\right)$ is slightly higher than 0.5 for alternative one, three and four. For the second alternative it is just below 0.5. In general it seems that the power distribution within the household is on average about fifty-fifty for male and female within the two-earner households.

We notice that the chosen functional form of the power function allows for 
all sample average values between zero and one. The power effects refer to a sub-sample of two- earner households. It is likely that the average value of the power coefficient is different for one-earner households. In Figure 1 we depict the distribution density function of $\pi_{n}$ over the sample for the four different alternatives.

\section{-Insert Figure 1 about here-}

Figure 1 shows that, although on average the household power is equally divided between male and female, there is much variation in the distribution of household power between individual households.

\section{-Insert Table 4 about here-}

We conclude that the power distribution seems to be reigned by the ratio of $\log$ hourly wages $\log \left(\frac{w_{m}}{w_{f}}\right)$, where $\beta_{m}$ and $\beta_{f}$ are about equal. This is empirical evidence for the idea that bargaining power in marriage is determined by differences in (potential) wage rates or rather earning powers. This is also argued by Pollak (2005).

The children effects are significant when the household preference parameter does not depend on family size and when we do not allow for gender differences in household productivity. However, when the preference for joint household production depends also on family size, the female tends to weight the total household production more heavily when family size increases. We do not find this effect for males. The children effect in the power function then becomes insignificant. Also when we allow for gender productivity differences we find that 
the children effects do not significantly influence the power distribution. Hence, it seems that the child effect that is found for the first alternative is captured by the effect of family size and gender differences in household productivity for the other alternatives.

\section{$5 \quad$ Wage, child and substitution effects}

In this model there are only two exogenous variables $w_{m}$ and $w_{f}$. How does labor supply and leisure consumption react on wage changes?

Let us assume that the wage vector $\left(w_{m}, w_{f}\right)=w$ changes by $\Delta w$, what will be the change in $z(w)$ ? We return to the system in (6). Let us assume $w^{(0)}, z^{(0)}$ was the situation ex ante and $w^{(1)}, z^{(1)}$ is the new equilibrium. We notice that the $(4 \times 10)$ - matrix $X$ is a function of $w$. Hence, differentiating the elements of the matrix $X$ also with respect to $w$, we add two columns to the matrix $U_{z z}$, getting the $(4 \times 6)$ - matrix $\left(\begin{array}{lll}U_{z z} & U_{z w}^{\prime}\end{array}\right)$. The matrix $U_{z w}^{\prime}$ is a $(4 \times 2)-$ matrix. However, we notice that according to equation $(2), \frac{\partial U_{h}}{\partial z}=$ $\pi \frac{\partial U_{m}}{\partial z}+(1-\pi) \frac{\partial U_{f}}{\partial z}=0$. Taking into account that $\pi$ depends on the wage vector as well, we get some additional derivatives. We have

$$
\begin{aligned}
U_{z z} & =\pi \cdot U_{m, z z}+(1-\pi) \cdot U_{f, z z} \\
U_{z w}^{\prime} & =\pi \cdot U_{m, z w}^{\prime}+(1-\pi) U_{f, z w}^{\prime}+\left[\frac{\partial \pi}{\partial w}\right]\left[U_{m, z}-U_{f, z}\right]^{\prime}
\end{aligned}
$$

where the last element is the product of a $(2 \times 1)$ - matrix and a $(1 \times 4)-$ matrix, resulting in a $(2 \times 4)$ - matrix. 
Denoting $z^{(1)}-z^{(0)}=\Delta z$, the new equilibrium has to satisfy the equation

$$
U_{z z} \Delta z+U_{z w}^{\prime} \Delta w=0
$$

and hence the wage effect matrix is

$$
\frac{\partial z}{\partial w}=-\left(U_{z z}\right)^{-1}\left[\pi U_{m, z w}^{\prime}+(1-\pi) U_{f, z w}^{\prime}+\left[\frac{\partial \pi}{\partial w}\right]\left[U_{m, z}-U_{f, z}\right]^{\prime}\right]
$$

We notice that the effect may be split up in a usual gross substitution effect and a separate power shift effect. Due to the identity $j h+w h+l e \equiv 24$ we find for the effects on job hours of the male and female

$$
\frac{\partial j h_{m}}{\partial w}=-\left(\frac{\partial w h_{m}}{\partial w}+\frac{\partial l e_{m}}{\partial w}\right)
$$

and

$$
\frac{\partial j h_{f}}{\partial w}=-\left(\frac{\partial w h_{f}}{\partial w}+\frac{\partial l e_{f}}{\partial w}\right)
$$

The corresponding elasticities are $\frac{\partial j h}{\partial w} \cdot \frac{w}{j h}$. The analysis has been performed under the assumption that households were in equilibrium in $z^{(0)}$. The elasticities in the sample average, that is all matrices evaluated in the sample gravity point, are presented in Table 4. This is also the case in Table 5 and 6 .

-Insert Table 4 about here-

Table 4 indicates that there is a backward bending labor-supply curve for 
both household members. The income effect dominates the substitution effect and when the hourly wage rate increases, individuals tend to substitute paid labor hours for leisure or household hours. We notice that the average wage elasticities are strongly influenced by the interaction effect. Letting the preference for joint household production depend on family size, the average wage elasticities are more negative for the male $(-0.994$ for alternative 2 and -1.019 for alternative four) and less negative for the female $(-0.591$ for alternative 2 and -0.048 for alternative four).

The labor-supply curve in terms of the hourly wage rate of the partner is forward bending. It seems that individuals tend to substitute leisure hours for paid job hours when the wage of the partner increases. With the exception of alternative 2 the empirical results suggest that individuals also substitute leisure hours for household production hours when the hourly wage of the partner increases. Both effects reflect the 'keeping-up-effect'. If the female contributes more in terms of money, the husband is motivated to keep up with her in terms of effort in earning money and being productive in the household. The same holds vice versa.

In general the estimation results suggest that the income effect dominates the substitution effect when the hourly wage rate increases. However, one would expect that if household income is not influenced by this substitution of paid labor for leisure, this will not influence the partner's behavior. It seems however that it does influence the partner's behavior. The individual whose wage increases tends to substitute towards a more favorable time allocation scheme, while the 
partner substitutes towards a more unfavorable time allocation scheme.

However, the fact that we consider a sample of two-earners might considerably influence the results. First, by considering only two-earner households we do not consider the labor participation decision making process by both partners. We merely observe the outcome of this decision process for the case where both partners do participate on the labor market. For these households household income is on average higher and it might be that as a consequence we find the backward bending labor supply curve for both household members.

We assume that income consists of three components, namely, the labor income of male and female and an additional unearned income $y_{u}$. The additional unearned income is defined as the net non-labor income earned last week. Hence, it is possible to obtain the unearned income effects:

$$
\frac{\partial z}{\partial y_{u}}=-\left(U_{z z}\right)^{-1}\left[U_{f, z y_{u}}^{\prime}+\pi \cdot\left(U_{m, z y_{u}}^{\prime}-U_{f, z y_{u}}^{\prime}\right)+\frac{\partial \pi}{\partial y_{u}} \cdot\left[U_{m, z}-U_{f, z}\right]^{\prime}\right]
$$

We see that an additional household income increase has an effect on all time variables simultaneously. The unearned income effects may be derived in the usual way and the results are shown in Table 5 .

\section{-Insert Table 5 about here-}

Notice that the distribution of $y_{u}$ in the sample is heavily skewed to the right or in other words the median value $y_{u}$ is smaller than the average value of $y_{u}$. Most households do not 'earn' much non-labor household income. Table 5 suggest for all alternatives that an increase of household income due to unearned 
income induces a shift to more leisure hours and for male and female, although the effect is small. The opposite effect is found for paid job hours with the exception the female job hour effect for alternative one. The effect on household production hours is ambiguous.

Unfortunately, the data provides no information on who is the provider of the non-labor income. Hence, it is impossible to split up $y_{u}$ in a male and a female part.

We may also assess the effect of having children using equation (18)

$$
\frac{\partial z}{\partial \ln (f s)}=-\left(U_{z z}\right)^{-1}\left[\left[\frac{\partial \pi}{\partial \ln (f s)}\right]\left[U_{m, z}-U_{f, z}\right]^{\prime}\right]
$$

The estimates in the sample gravity point are presented Table 6 .

\section{-Insert Table 6 about here-}

The column indicates the number of children between certain age levels. Therefore $c 02$ refers to the number of children present in the household that are between zero and two, and so on.

We see that the child effects of young children are considerable but that the child effects for children above 5 are not very robust. We notice that the child effects in the power function are on average not significant, which might explain the ambiguous results. Furthermore, child effects will most likely be different when one-earner household would be considered as well.

It appears that the female tends to work less hours on the labor market when there are more children present in the household younger than 5 . The 
male on the other hand tends to work more hours on the labor market when there are more young children present in the household. As there are more young children in the household the female is usually the one that specializes in household tasks while the male specializes on the labor market tasks. Hence, the female substitutes paid labor hours for household production hours, while the male substitutes from leisure towards job marked hours.

\section{Conclusion}

In this paper we estimate the separate utility functions of male and female on the basis of a collective household model. We find that the utility functions of males and females are significantly different, which provides additional evidence for the collective approach. Although the model is non-linear in the outcome variables male leisure, female leisure, and so on, it is possible to estimate the utility parameters by means of a Seemingly Unrelated Regression approach.

We estimate four alternative models. For the first and second alternative it is assumed that the number of household hours of male and female are perfect substitutes, this assumption is relaxed in the third and fourth alternative. For the second and fourth alternative an interaction term is included, where joint household production is interacts with family size, while we assume that there is no interaction effect in the first and third alternative.

The estimation results appear to be robust for the four different alternatives. When we do not assume that household hours of male and female are 
perfect substitutes we find that the male is slightly more productive in performing household tasks. This might be explained due to the fact that the female spends on average more time on household tasks than men. Spending one additional hour on household production might then be less productive compared to one additional hour of household production hour by the male. In other words, for male and female it might hold that household productivity is a decreasing function of the number of household hours. The most important variables in the utility function for the four different alternatives appear to be leisure and household income, for both male and female. When we assume that the preference for total household production is influenced by family size we find that this preference is influenced by family size for the female, while this is not the case for the male.

The derived wage elasticities show that both partners have a backward bending labor supply curve and hence our findings show that the labor supply curve of women resembles that of men more now than in the past. One explanation for the backward bending labor supply curve for women is that there are now more women with high income than in the past. For these women, apparently, the income effect dominates the substitution effect, making that they reduce their hours of work rather than increasing it when their own wage rate increases.

Research on female labor supply conducted in the 1980's and 1990's generally found high wage elasticities. Typically a wage elasticity of around 1 was found. Furthermore, the female labor supply curve was forward bending for the entire range of female wages. That now seems to have changed because of the increase 
of female labor supply. Apparently women's behavior on the labor market resembles male labor supply, although the descriptive statistics still indicate that the hourly wage rate and the amount of labor supply is on average lower for females compared to males.

We also explained the power distribution within the household. We find for this sample of two-earner households that on average the power is about evenly distributed between the partners. Still there is considerable variation between households. The power distribution depends mainly on the relative hourly wages (earning potentials) since the coefficient of the male's wage is about equal to the coefficient of the female's wage. The relative power of the female compared to that of her partner is increased if there are young children in the household when we assume that there is no family size interaction with household production and that household hours of male and female are perfect substitutes. When we relax these assumptions the child effect disappears.

To the best of our knowledge we have not encountered these empirical results in the scientific literature. Nevertheless, the model discussed in this paper can be extended in several ways.

First, it seems interesting to examine how results vary with different model specifications and how results vary when utility functions are assumed to be heterogeneous. Second, it might be that other characteristics are important when discussing the division of labor and household tasks, which on its turn influence the power distribution. Third, we only considered a special sub-sample of two-earner households. This simplified the analysis considerably, as one-earner 
families reflect a corner solution of the household decision problem. However, since we do not consider one-earner families in the model, the estimation results are likely to be biased. Fourth, it is interesting to empirically estimate a collective model of time allocation over time, since it is then possible to observe or not observe changes in the division of labor and household tasks, due to household specific events. 


\section{References}

Apps, P. \& R. Rees (1997), 'Collective supply and household production', Journal of Political Economy 105(1), 178-190.

Ashworth, J. \& D.T. Ulph (1981), 'Household models, in c.v. brown (eds). taxation and labour supply.'.

Beblo, M. (1999), Intrafamily Time Allocation: A Panel-Econometric Analysis, In: Merz, J. und Ehling, M. (Hrsg.), Time Use-Research, Data and Policy, Baden-Baden, pp. 473-489.

Blundell, R., P.A. Chiappori, T. Magnac \& Costas Meghir (2001), Collective labor supply: Heterogeneity and nonparticipation. working paper - The Institute for Fiscal Studies.

Browning, M. (2000), 'The saving behavior of a two-person household', Scandinavian Journal of Economics 102(2), 235-251.

Browning, M., F, Bourguignon, P. A. Chiappori \& V. Lechene (1994), 'Children and household economic behavior', The Journal of Political Economy pp. 1067-1096.

Browning, M. \& M. Gørtz (2005), Spending time and money within the household. working paper Institute of Economics, Copenhagen.

Browning, M. \& P. A. Chiappori (1998), 'Efficient intra-household allocations: A general characterization and empirical tests', Econometrica pp. 12411278. 
Browning, M., P.A. Chiappori \& V. Lechene (2004), 'Collective and unitary models: a clarification', Working paper .

Carlin, P. (1990), 'Intra-family bargaining and time allocation', Research in Population Economics 7, 215-243.

Cheng, Z. \& F. Woolley (2001), 'A cournot-nash model of family decision making', The Economic Journal 111, 722-748.

Chiappori, P. A. (1988), 'Rational household labor supply', Econometrica $\mathbf{5 6}(1), 63-90$.

Chiappori, P. A. (1997), 'Introducing household production in collective models of labor supply', The Journal of Political Economy 105(1), 191-209.

Halberg, D. (2003), 'Synchronous leisure, jointness and household labor supply', Labor Economics 10(2), 185-203.

Hallberg, D. \& A. Klevmarken (2003), 'Time for children a study of parents' time allocation', Journal of Population Economics 16(2), 205-226.

Hamermesh, D. (1996), 'The timing of work time: evidence from the us and germany', Konjunkturpolitik 42, 1-22.

Hamermesh, D. (2000), 'Togetherness: Spouses' synchronous leisure, and the impact of children', NBER Working Paper (7455).

Hamermesh, D. (2002), 'Timing, togetherness and time windfalls', Journal of Population Economics 15, 601-632. 
Jenkins, S. P. \& L. Osberg (2005), "Nobody to play with? The implications of leisure coordination", Chapter 5, in Hamermesh and Pfann (eds), The economics of time use, contributions to economic analysis, Vol. 271, Elsevier, pp. $113-145$.

Kooreman, P. \& A. Kapteyn (1990), 'On the empirical implementation of some game theoretic models of household labor supply', The Journal of Human Resources 25(4), 584-598.

Leuthold, J.H. (1968), 'An empirical study of formula income transfers and the work decision of the poor', Journal of Human Resources 3, 312-323.

Lundberg, S., R. Pollak \& T.J. Wales (1997), 'Do husbands and wives pool their resources? evidence from the u.k. child benefit', Journal of Human Resources 32(3), 463-480.

McElroy, M. (1990), 'The empirical content of nash bargained household behavior', The Journal of Human resources 25(4), 559-583.

Pollak, R. A. (2005), Bargaining power in marriage: Earnings, wage rates and household production. Working Paper.

van Klaveren, C.P.B.J. \& H. Maassen van den Brink (2005), Intra-household work time synchronization. Working Paper.

Vermeulen, F. (2002), 'Collective household models: principles and main results', Journal of Economic Surveys 16(4), 534-564. 
Ward-Batts, J. (2002), Out of the wallet and into the purse: Using micro data to test income pooling. Claremont Colleges Working Paper in Economics, No. 2002-11. 
Table 1: Summary Statistics

\begin{tabular}{lccccc}
\hline \hline & & & & & \\
& \#obs. & mean & Std. Dev. & Min. & Max. \\
Leisure hours male & 1497 & 118.742 & 9.470 & 66 & 155 \\
Household hours male & 1497 & 5.328 & 4.205 & 1 & 30 \\
Job hours male & 1497 & 43.931 & 8.953 & 7 & 100 \\
Leisure hours female & 1497 & 121.707 & 11.616 & 63 & 158 \\
Household hours female & 1497 & 13.917 & 8.548 & 1 & 70 \\
Job hours female & 1497 & 32.376 & 11.460 & 2 & 80 \\
& & & & & \\
Hourly wage male & 1497 & 7.947 & 8.526 & 0.694 & 310.129 \\
Hourly wage female & 1497 & 6.450 & 2.894 & 0.468 & 28.868 \\
\hline \hline
\end{tabular}


Table 2: Parameter estimates for $\alpha$

\begin{tabular}{|c|c|c|c|c|}
\hline \multirow[t]{2}{*}{ Alternative 1} & \multicolumn{2}{|c|}{ Male } & \multicolumn{2}{|c|}{ Female } \\
\hline & Estimate & $z$-value & Estimate & $z$-value \\
\hline leisure & 0.755 & 256.33 & 0.778 & 213.67 \\
\hline household work & 0.003 & 20.93 & 0.004 & 7.3 \\
\hline household production $(H)$ & 0.014 & 7.73 & 0.032 & 15 \\
\hline \multicolumn{5}{|l|}{$H$ interaction term } \\
\hline household income & 0.261 & 57.33 & 0.204 & 60.23 \\
\hline job working hours & -0.033 & -13.29 & -0.017 & -21.59 \\
\hline \multirow[t]{2}{*}{ Alternative 2} & \multicolumn{2}{|c|}{ Male } & \multicolumn{2}{|c|}{ Female } \\
\hline & Estimate & $z$-value & Estimate & $z$-value \\
\hline leisure & 0.757 & 219.190 & 0.823 & 193.330 \\
\hline household work & 0.004 & 23.510 & 0.002 & 3.840 \\
\hline household production $(H)$ & 0.013 & 6.010 & 0.019 & 9.700 \\
\hline$H$ interaction term & 0.002 & 0.570 & 0.013 & 3.910 \\
\hline household income & 0.293 & 61.690 & 0.180 & 54.720 \\
\hline job working hours & -0.069 & -26.470 & -0.037 & -29.140 \\
\hline \multirow[t]{2}{*}{ Alternative 3} & \multicolumn{2}{|c|}{ Male } & \multicolumn{2}{|c|}{ Female } \\
\hline & Estimate & $z$-value & Estimate & $z$-value \\
\hline leisure & 0.739 & 259.590 & 0.794 & 224.260 \\
\hline household work & 0.003 & 17.360 & 0.006 & 13.830 \\
\hline household production $(H)$ & 0.026 & 15.490 & 0.016 & 7.990 \\
\hline \multicolumn{5}{|l|}{$H$ interaction term } \\
\hline household income & 0.268 & 62.220 & 0.203 & 61.730 \\
\hline job working hours & -0.036 & -15.540 & -0.019 & -23.930 \\
\hline \multirow[t]{2}{*}{ Alternative 4} & \multicolumn{2}{|c|}{ Male } & \multicolumn{2}{|c|}{ Female } \\
\hline & Estimate & $z$-value & Estimate & $z$-value \\
\hline leisure & 0.741 & 237.250 & 0.767 & 206.160 \\
\hline household work & 0.003 & 19.070 & 0.005 & 11.160 \\
\hline household production $(H)$ & 0.020 & 9.130 & 0.015 & 6.080 \\
\hline$H$ interaction term & 0.005 & 1.150 & 0.028 & 6.380 \\
\hline household income & 0.269 & 62.160 & 0.203 & 59.650 \\
\hline \multirow[t]{2}{*}{ job working hours } & -0.037 & -15.640 & -0.018 & -23.900 \\
\hline & Alt. 1 & Alt. 2 & Alt. 3 & Alt. 4 \\
\hline $\bar{\pi}_{n}$ & 0.532 & 0.471 & 0.542 & 0.534 \\
\hline$\gamma$ & 1 & 1 & 0.85 & 0.925 \\
\hline $\mathrm{N}$ & 1497 & 1497 & 1497 & 1497 \\
\hline
\end{tabular}


Table 3: Performing a Wald test for $\alpha^{m}-\alpha^{f}=\mathbf{0}$ for each preference type

\begin{tabular}{lcccc} 
& \multicolumn{4}{c}{ Prob $>\chi^{2}$} \\
\cline { 2 - 5 } Compare $\alpha_{m}$ and $\alpha_{f}$ w.r.t & Alt. 1 & Alt. 2 & Alt. 3 & Alt. 4 \\
\hline Leisure & 0 & $\mathrm{x}$ & $\mathrm{x}$ & $\mathrm{x}$ \\
Household work & $\mathrm{x}$ & 0 & $\mathrm{x}$ & $\mathrm{x}$ \\
Joint household production $(H)$ &. & $\mathrm{x}$ & $\mathrm{x}$ & 0 \\
$H$ interaction term & $\mathrm{x}$ & $\mathrm{x}$ & $\mathrm{x}$ & $\mathrm{x}$ \\
Household income & $\mathrm{x}$ & $\mathrm{x}$ & $\mathrm{x}$ & $\mathrm{x}$ \\
Job working hours &
\end{tabular}

Note: 0 indicates $\alpha_{m^{-} \alpha_{f}}=0, \mathrm{x}$ indicates that $\alpha_{m^{-} \alpha_{f}} \neq 0$ difference 
Table 4: Estimates of the Power Function $\pi_{n}$

\begin{tabular}{|c|c|c|c|c|}
\hline & \multicolumn{2}{|c|}{ Alternative 1} & \multicolumn{2}{|c|}{ Alternative 2} \\
\hline & Estimate & z-value & Estimate & z-value \\
\hline $\log \left(w_{\text {male }}\right)$ & $0.593^{* * *}$ & 25.710 & $0.592^{* * *}$ & 22.620 \\
\hline $\log \left(w_{\text {female }}\right)$ & $-0.562^{* * *}$ & -25.260 & $-0.606^{* * *}$ & -23.260 \\
\hline $\log (\#$-children $0 / 2+1)$ & $-0.094^{* *}$ & -2.320 & -0.078 & -1.650 \\
\hline $\log (\#$-children $3 / 4+1)$ & $-0.091^{* *}$ & -2.170 & -0.062 & -1.270 \\
\hline $\log (\#$-children $5 / 11+1)$ & $-0.056^{* *}$ & -2.370 & -0.023 & -0.860 \\
\hline $\log (\#$-children $12 / 16+1)$ & -0.038 & -1.320 & 0.011 & 0.340 \\
\hline $\log (\#$-children $>16+1)$ & -0.052 & -0.980 & 0.002 & 0.040 \\
\hline $\log \left(\right.$ age $\left._{\text {male }}\right)$ & 0.014 & 0.210 & -0.056 & -0.710 \\
\hline $\log \left(\right.$ age $\left.e_{\text {emale }}\right)$ & -0.036 & -0.520 & 0.019 & 0.240 \\
\hline $\log \left(y_{u}+1\right)$ & $0.010^{*}$ & 1.750 & -0.004 & -0.540 \\
\hline \multirow[t]{3}{*}{$\mathrm{N}$} & 1497 & & 1497 & \\
\hline & \multicolumn{2}{|c|}{ Alternative 3} & \multicolumn{2}{|c|}{ Alternative 4} \\
\hline & Estimate & z-value & Estimate & z-value \\
\hline $\log \left(w_{\text {male }}\right)$ & $0.613^{* * *}$ & 26.310 & $0.625^{* * *}$ & 26.200 \\
\hline $\log \left(w_{\text {female }}\right)$ & $-0.621^{* * *}$ & 26.820 & $-0.628^{* * *}$ & 26.590 \\
\hline $\log (\#$-children $0 / 2+1)$ & -0.025 & -0.620 & -0.038 & -0.910 \\
\hline $\log (\#$-children $3 / 4+1)$ & -0.023 & -0.560 & -0.039 & -0.900 \\
\hline $\log (\#$-children $5 / 11+1)$ & 0.001 & 0.050 & -0.009 & -0.380 \\
\hline $\log (\#$-children $12 / 16+1)$ & 0.012 & 0.410 & 0.004 & 0.140 \\
\hline $\log (\#$-children $>16+1)$ & -0.006 & -0.110 & -0.011 & -0.200 \\
\hline $\log \left(\right.$ age $\left._{\text {male }}\right)$ & -0.024 & -0.340 & -0.026 & -0.370 \\
\hline $\log ($ age female $)$ & 0.024 & 0.330 & 0.016 & 0.210 \\
\hline $\log \left(y_{u}+1\right)$ & 0.005 & 0.810 & 0.006 & 0.910 \\
\hline $\mathrm{N}$ & 1497 & & 1497 & \\
\hline
\end{tabular}

Note: ${ }^{*}$ significant at $10 \%$ level, ${ }^{* *}$ significant at $5 \%$ level, *** significant at $1 \%$ level. 


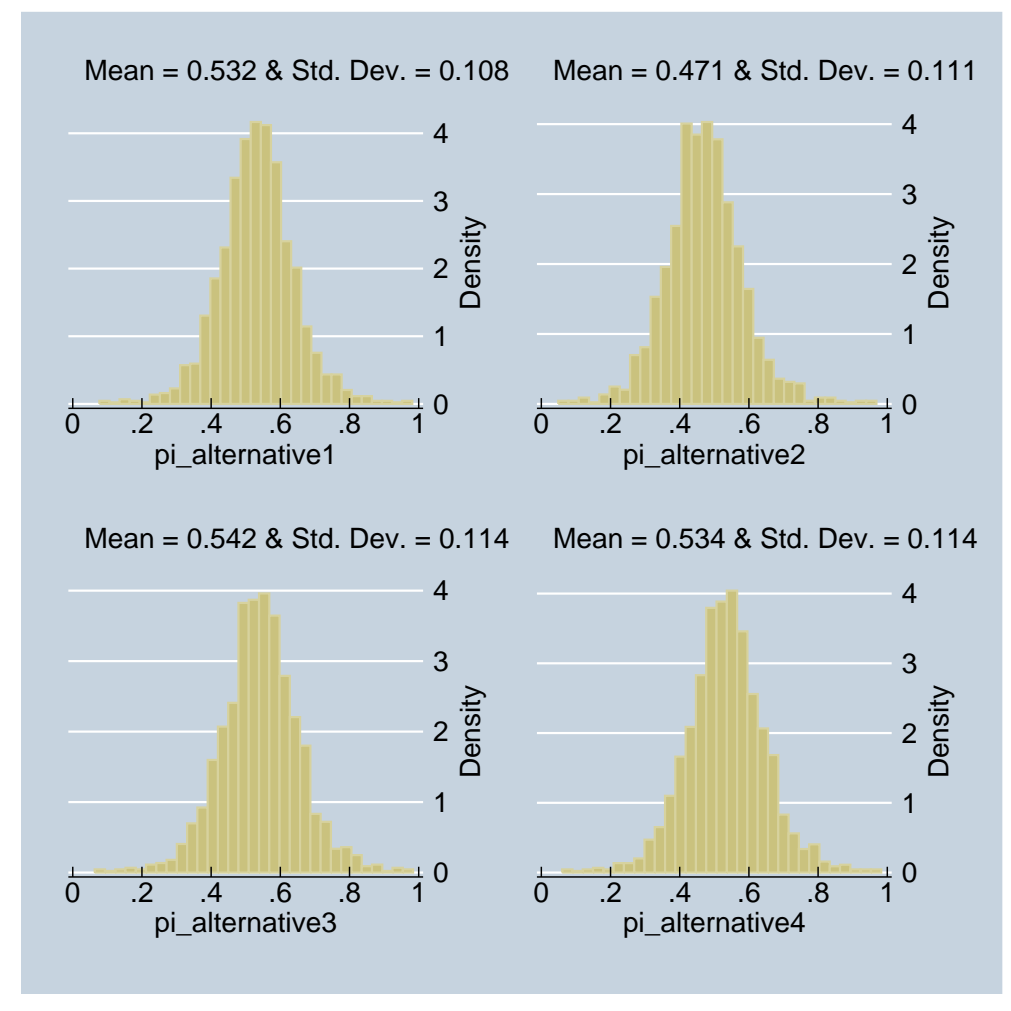

Figure 1: Distribution graphs of $\pi_{n}$ for the different alternatives 
Table 4: Average Wage Elasticities

\begin{tabular}{lrrrr}
\hline \hline & \multicolumn{2}{c}{ Alternative $\mathbf{1}$} & \multicolumn{2}{c}{ Alternative 2 } \\
& $\mathbf{w}_{m}$ & $\mathbf{w}_{f}$ & $\mathbf{w}_{m}$ & $\mathbf{w}_{f}$ \\
$l e_{m}$ & 0.211 & -0.197 & 0.186 & -0.230 \\
$w h_{m}$ & -1.409 & 0.805 & -2.027 & 1.421 \\
$j h_{m}$ & -0.795 & 0.862 & -0.994 & 1.138 \\
$l e_{f}$ & -0.237 & 0.195 & -0.224 & 0.228 \\
$w h_{f}$ & 0.704 & -0.577 & -0.825 & 0.856 \\
$j h_{f}$ & 1.242 & -1.136 & 0.493 & -0.591 \\
& \multicolumn{2}{c}{ Alternative 3 } & Alternative 4 \\
& $\mathbf{w}$ & $\mathbf{w}$ & $\mathbf{w}$ & $\mathbf{w}_{f}$ \\
$l e_{m}$ & 0.134 & -0.144 & 0.261 & -0.291 \\
$w h_{m}$ & -2.151 & 1.757 & -1.830 & 0.584 \\
$j h_{m}$ & -0.283 & 0.353 & -1.019 & 1.238 \\
$l e_{f}$ & -0.260 & 0.241 & -0.073 & 0.118 \\
$w h_{f}$ & 1.256 & -1.272 & 1.021 & -0.587 \\
$j h_{f}$ & 1.266 & -1.042 & -0.429 & -0.048 \\
& & & & \\
\hline \hline
\end{tabular}

Table 5: Average Unearned Income Elasticities

\begin{tabular}{lrrrr}
\hline \hline & Alt. 1 & Alt. 2 & Alt. 3 & Alt. 4 \\
& & & & \\
$l e_{m}$ & 0.035 & 0.034 & 0.019 & 0.028 \\
$w h_{m}$ & 0.105 & 0.138 & -0.061 & 0.061 \\
$j h_{m}$ & -0.108 & -0.110 & -0.037 & -0.091 \\
$l e_{f}$ & 0.000 & 0.010 & 0.022 & 0.005 \\
$w h_{f}$ & -0.004 & -0.014 & 0.123 & 0.013 \\
$j h_{f}$ & 0.008 & -0.038 & -0.155 & -0.023 \\
& & & & \\
$\bar{y}_{u}$ & 40.627 & & & \\
median $_{y_{u}}$ & 17.775 & & & \\
$\sigma_{y_{u}}$ & 73.420 & & & \\
\hline \hline
\end{tabular}


Table 6: Child Effects

\begin{tabular}{|c|c|c|c|c|c|}
\hline \multicolumn{6}{|c|}{ Alternative 1} \\
\hline & c02 & c34 & c511 & c1215 & c1618 \\
\hline$l e_{m}$ & -0.0042 & -0.0051 & -0.0106 & -0.0018 & -0.0024 \\
\hline$w h_{m}$ & 0.1002 & -0.0050 & -0.0122 & 0.0287 & -0.0124 \\
\hline$j h_{m}$ & -0.0309 & 0.0134 & 0.0280 & -0.0026 & 0.0078 \\
\hline$l e_{f}$ & 0.0040 & 0.0056 & 0.0101 & 0.0030 & 0.0028 \\
\hline$w h_{f}$ & -0.1085 & 0.0133 & 0.0109 & -0.0034 & 0.0073 \\
\hline$j h_{f}$ & 0.0030 & -0.0129 & -0.0143 & 0.0140 & -0.0124 \\
\hline \multicolumn{6}{|c|}{ Alternative 2} \\
\hline & c02 & c34 & c511 & c1215 & c1618 \\
\hline$l e_{m}$ & -0.0076 & -0.0037 & -0.0066 & 0.0009 & 0.0000 \\
\hline$w h_{m}$ & -0.0363 & 0.0137 & 0.0140 & -0.0070 & -0.0008 \\
\hline$j h_{m}$ & 0.0244 & 0.0005 & 0.0060 & 0.0020 & 0.0002 \\
\hline$l e_{f}$ & 0.0049 & 0.0023 & 0.0023 & -0.0008 & 0.0000 \\
\hline$w h_{f}$ & 0.0191 & -0.0159 & -0.0608 & 0.0188 & 0.0010 \\
\hline$j h_{f}$ & -0.0321 & 0.0025 & -0.0050 & 0.0011 & 0.0000 \\
\hline \multicolumn{6}{|c|}{ Alternative 3} \\
\hline & c02 & c34 & c511 & c1215 & c1618 \\
\hline$l e_{m}$ & -0.0083 & -0.0012 & 0.0003 & 0.0013 & -0.0004 \\
\hline$w h_{m}$ & -0.1142 & -0.0027 & 0.0005 & -0.0155 & -0.0040 \\
\hline$j h_{m}$ & 0.0445 & 0.0035 & -0.0009 & 0.0011 & 0.0018 \\
\hline$l e_{f}$ & 0.0098 & 0.0012 & -0.0003 & -0.0017 & 0.0005 \\
\hline$w h_{f}$ & 0.0835 & 0.0033 & -0.0002 & 0.0128 & 0.0019 \\
\hline$j h_{f}$ & -0.0745 & -0.0017 & 0.0012 & 0.0002 & -0.0026 \\
\hline \multicolumn{6}{|c|}{ Alternative 4} \\
\hline & c02 & c34 & c511 & c1215 & c1618 \\
\hline$l e_{m}$ & -0.0204 & -0.0043 & -0.0086 & 0.0041 & 0.0008 \\
\hline$w h_{m}$ & -0.0713 & -0.0328 & -0.0319 & 0.0329 & -0.0027 \\
\hline$j h_{m}$ & 0.0609 & 0.0180 & 0.0260 & -0.0142 & -0.0094 \\
\hline$l e_{f}$ & 0.0346 & 0.0052 & 0.0192 & -0.0094 & 0.0032 \\
\hline$w h_{f}$ & 0.0504 & 0.0262 & 0.0182 & -0.0164 & -0.0009 \\
\hline$j h_{f}$ & -0.2644 & -0.0287 & -0.1299 & 0.0700 & -0.0279 \\
\hline
\end{tabular}

